\title{
LEVANTAMENTO DE PROPRIEDADES MECÂNICAS DE COMPÓSITOS DE MATRIZ DE POLIPROPILENO ADICIONADOS COM FIBRAS LONGAS DE BAMBU *
}

\author{
Renardir Peixoto Maciel Júnior ${ }^{1}$ \\ Roberto Abreu Alencar ${ }^{2}$ \\ Santino Loruan Silvestre de Melo ${ }^{3}$ \\ Enio Pontes de Deus ${ }^{4}$
}

\begin{abstract}
Resumo
A importância do desenvolvimento sustentável, tendo como base um ambiente saudável para as gerações futuras, leva a se pensar em como as organizações poderiam desenvolver materiais menos danosos ao ambiente com boas propriedades e pelo menor custo. A proposta de aproveitamento de fibras vegetais para utilização em desenvolvimento de compósitos de matriz polimérica reforçados pelas mesmas é a motivação da pesquisa visando obter um compósito com melhores propriedades mecânicas e químicas do que sua matéria prima. Por virtude da importância do desenvolvimento desses materiais, a caracterização mecânica da fibra, da matriz e, finalmente, do compósito através de ensaios destrutivos e não destrutivos é fundamental para estudo de sua aplicação. Após a obtenção dos dados, percebeu-se que a adição das fibras melhorou as propriedades mecânicas do compósito resultante. Mostrando, portanto, resultados promissores para o desenvolvimento desses materiais, promovendo assim um material mais barato e de melhor propriedade mecânica, além de uma alta leveza. Em suma, os resultados estão de acordo com o esperado, impulsionando assim um melhor estudo desses materiais, por exemplo, realizando outros ensaios, como ensaios de impacto.
\end{abstract}

Palavras-chave: Fibra de Bambu; Compósito; Correli; Polímero

\section{MECHANICAL CHARACTERIZATION OF COMPOSITE POLYPROPYLENE MATRIZ ADDED BAMBOO LONG FIBERS}

\begin{abstract}
The importance of sustainable development, based on the desirability of a healthy environment for future generations, prompts one to think about how organizations could develop materials which are not only less harmful to the environment, but also possess excellent properties and cost less. The proposed use of plant fibers for use in the development of polymer matrix composites reinforced by them is the reason for this research on how to obtain a composite with better properties than the raw material from which it is made. By virtue of the importance of developing these materials, the mechanical characteristics of the fiber, matrix, and finally the composite through destructive and non-destructive testing, is critical in order to study its application. After obtaining the data, it is clear that the addition of fiber improved the mechanical properties of the resulting composite. Showing therefore promising results for the development of such materials, thereby promoting a cheaper and better mechanical material property, and a high lightness. In summary, the results are as expected, thereby driving a better study of these materials, for example, by performing other tests, such as impact tests.
\end{abstract}

Keywords: Bamboo Fiber; Composite; Correli; Polymer. 
1 Engenharia Metalúrgica/graduando, bolsista de iniciação científica, Departamento de Engenharia Metalúrgica e Materiais, Universidade Federal do Ceará, Fortaleza, Ceará e Brasil.

2 Engenharia Metalúrgica/graduando, bolsista de iniciação científica, Departamento de Engenharia Metalúrgica e Materiais, Universidade Federal do Ceará, Fortaleza, Ceará e Brasil.

3 Físico/bacharelado, bacharel, Doutorando, Departamento de Engenharia Metalúrgica e Materiais, Universidade Federal do Ceará, Fortaleza, Ceará e Brasil.

4 Engenheiro Civil, Doutorado, Professor Adjunto /Orientador, Departamento de Engenharia Metalúrgica e Materiais, Universidade Federal do Ceará, Fortaleza, Ceará e Brasil. 


\section{INTRODUÇÃO}

A era dos polímeros, que se inicia basicamente no século XIX e alcança até os dias de hoje, está relacionada ao desenvolvimento crescente em diversas áreas da humanidade, como o setor automobilístico, eletroeletrônico e medicinais até setores como os de embalagem (HAGE, 1998, pag. 1). Obter materiais e métodos com propriedades concisas e específicas para determinada aplicação, exigem ainda mais dos materiais a serem produzidos, fazendo com que os polímeros e suas respectivas blendas e compósitos reafirmem a sua magnitude de trabalhabilidade. As mudanças e avanços tecnológicos ocorridos até hoje, estão intimamente ligados a disponibilidade de materiais adequados a aplicações específicas.

Os polímeros ocupam lugar de destaque nesse quesito, pois são diversas as variáveis que alteram significativamente as propriedades finais do material que se busca. Como exemplo, pode-se citar o Propileno $(\mathrm{C} 3 \mathrm{H} 6)$, obtido do petróleo pela fração de nafta que se obtém da destilação fracionada do óleo cru (CANEVAROLO, pag. 32, 2002). Seu monômero, que por poliadição (ou polimerização em cadeia) gera o polímero Polipropileno (PP) que atuará como matriz polimérica do compósito utilizado nesse trabalho. Variáveis de estado como temperatura, tempo e pressão limitam o crescimento da cadeia polimérica, assim como a sua taticidade, delimitando assim as propriedades mecânicas químicas e físicas que se pretendem atingir.

Quando a modificação das propriedades dos materiais ou a disponibilidade de matéria prima é limitada, gerando impacto negativo a natureza, os procedimentos químicos e físicos de alteração da matéria prima pura já não são suficientes. Nesse caso, as blendas e os compósitos se tornam uma alternativa viável. Tanto as blendas como os compósitos são excelentes modificadores das propriedades mecânicas dos polímeros, onde se pode substituir parte da matéria prima principal, fazendo com que o produto final melhores as propriedades do material em direções específicas ou mesmo em todas as direções, para que ocorra uma diminuição de utilização da matéria prima principal.

Os compósitos podem ser reforçados por fibras de tal forma que ambas, fibras e matriz, conservem suas identidades química e física e, ainda, produzam uma combinação de propriedades que não podem ser conseguidas com um dos constituintes agindo sozinho (MALLICK, 1988).

O desenvolvimento de compósitos poliméricos com fibras vegetais naturais, advindas da biodiversidade regional predominante, se tornou difundido entre a comunidade universitária pesquisadora que investiga os compósitos poliméricos biodegradáveis devido a sua importância de caráter sócio ambiental (MARINELLI, pag. 93, 2008.

As propriedades mecânicas do reforço fibroso em compósitos poliméricos dependem, principalmente, de três fatores: módulo de resistência da fibra, estabilidade química da matriz polimérica e ligação efetiva entre matriz e reforço na transferência de forças através da interface (KURUVILLA et al., 1996). Dentre as resinas termoplásticas viáveis para o emprego de fibras destaca-se a resina de polipropileno (PP) por sua versatilidade em relação a sua formulação tornando-a adaptável a múltiplas aplicações. A indústria automotiva é a principal impulsionadora para o desenvolvimento dos materiais compósitos estruturais reforçados com fibras naturais que teve seu início por razões técnicas e comerciais, ou seja, além do menor custo quando comparadas com as fibras de vidro, as fibras de bambu apresentam um potencial de redução do peso do veículo em até $40 \%$ quando 
comparado com as fibras de vidro (DOS SANTOS, 2006), possuindo ainda melhores propriedades de isolamento acústico e térmico, apresentam maior segurança nas colisões, são renováveis e de fácil reciclagem (ROMÃO, 2003).

Além da importância do desenvolvimento desse tipo de materiais, vale ressaltar o incremento e aperfeiçoamento de uma técnica não destrutiva de medição de deslocamento, velocidade e deformação para a caracterização mecânica. Em particular, a técnica de Correlação de Imagem Digital merece destaque pela elevada aplicabilidade em diversos campos da mecânica experimental.

\section{MATERIAIS E MÉTODOS}

\subsection{Materiais Utilizados}

Os componentes desse trabalho são respectivamente a matriz polimérica, a fase dispersa e reagentes de modificação superficial de fibras poliméricas.

Matriz: Utiliza-se o Polipropileno Isotático, assim como seu Reciclado como matriz dos compósitos fabricados. O material foi cedido pela empresa PLASTSAN, em agosto de 2014, através de uma parceria entre o LAMEFF e a empresa. O material veio na forma de grânulos, o qual material não continha aditivos, com exceção dos reagentes de descoloração utilizados para a obtenção do PPir. O levantamento das propriedades dos materiais não foi recebido da empresa, visto que esta possui dados em que os aditivos são levados em consideração.

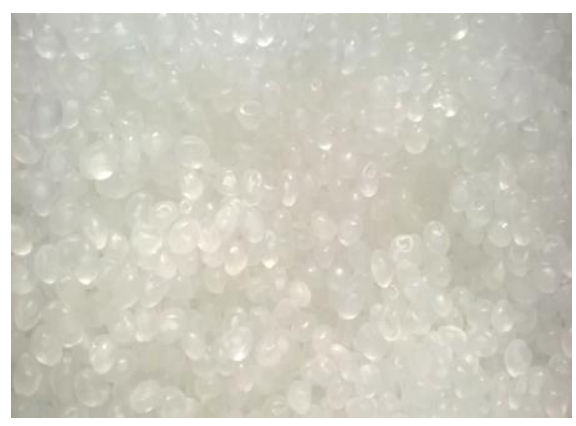

Fonte: próprio autor. Figura1: PPi virgem

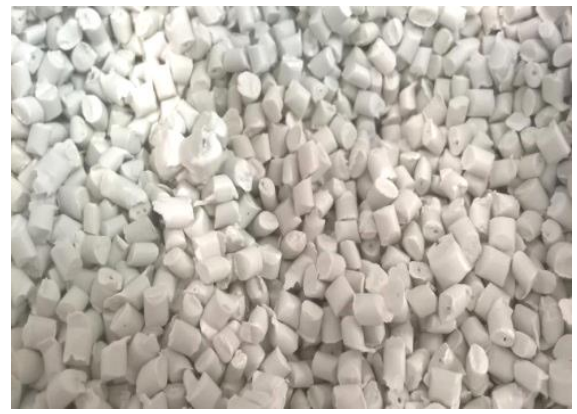

Fonte: próprio autor. Figura 2 : PPi recilado

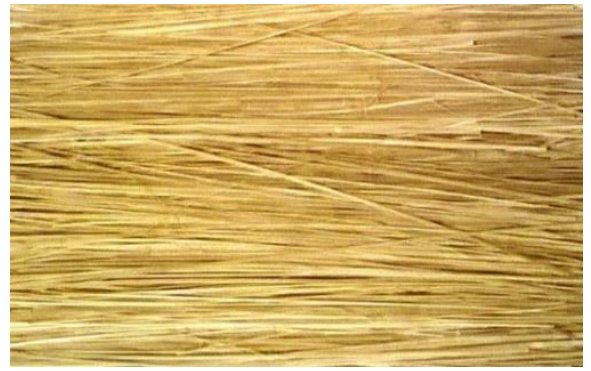

Fonte: próprio autor.

Figura 3: Fibra extraída do bambu 
Fase Dispersa: Foi colhido Bambu da família Bambusa de espécie Vulgaris (Bambusa Vulgaris), de touceiras controladas da Universidade Federal do Ceará. Os colmos, parte essencial e que é de fundamental interesse nesse trabalho, foram cerrados para a extração dos entrenós na Oficina do Departamento de Física da Universidade Federal do Ceará para posteriormente serem descascadas e desfibradas.

\subsection{Técnicas para obtenção dos compósitos}

Os compósitos foram preparados em um molde construído para tal finalidade, com pressão e temperatura controlada para a confecção dos laminados e seus corpos de prova.

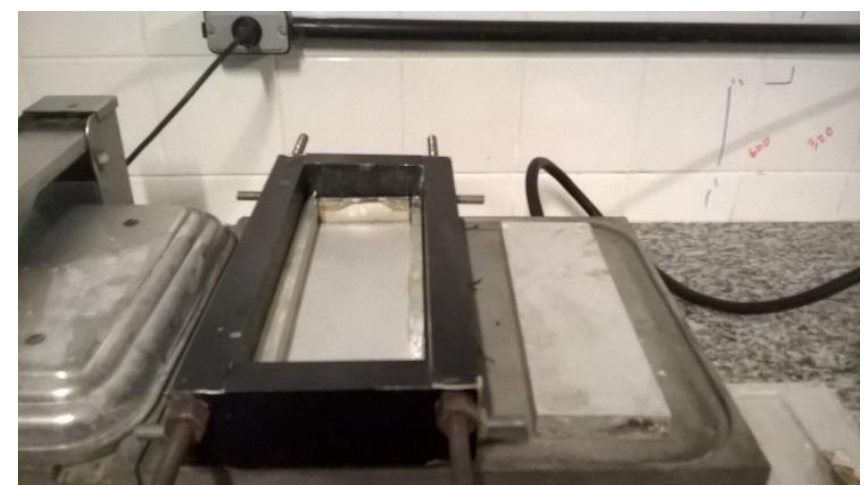

Fonte: próprio autor

Figura 1: Molde Confeccionado

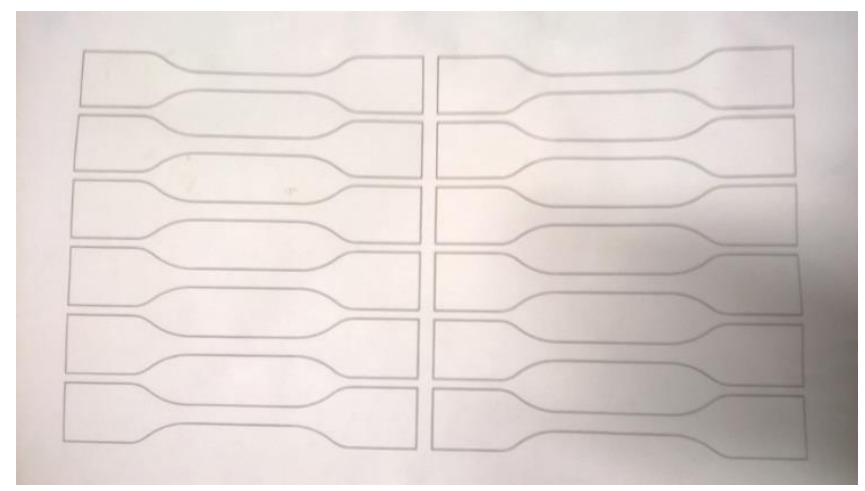

Fonte: próprio autor.

Figura 6: Folha Padrão da Norma ASTM D638

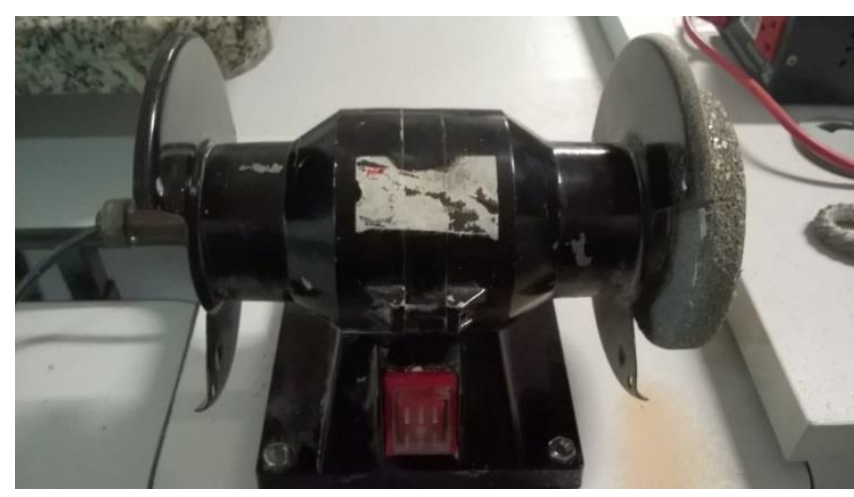

Fonte: próprio autor.

Figura 5: Esmeril usado para usinagem dos CPs

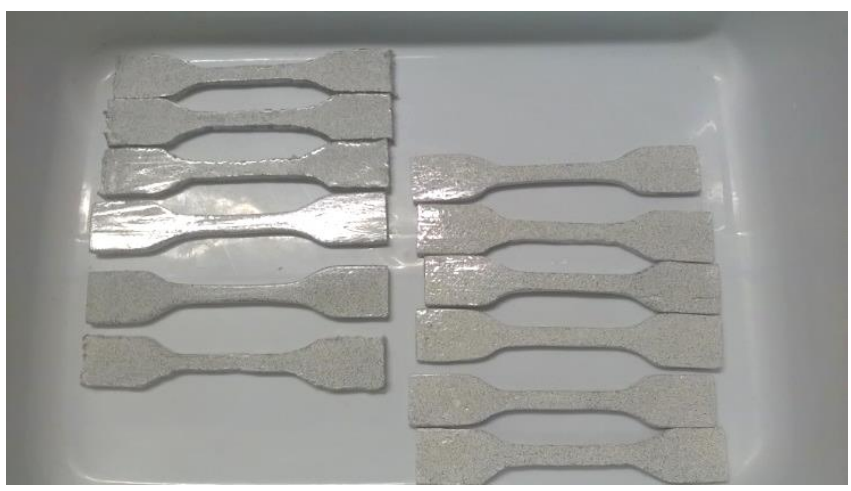

Fonte: próprio autor.

Figura 7: Corpos de Prova finalizados

\subsubsection{Compósito com fase dispersa}

O compósito com suas respectivas fases dispersas orientadas em um direção. Para que as fibras não se sobreponham na matriz quando esta está com sua melhor temperatura de viscosidade, será criada uma malha de fibras alinhadas e dispostas uma ao lado da outra, com três fibras a $90^{\circ}$ para que estas não se dispersem. Após esse procedimento, o molde é aquecido até que a temperatura de 
fusão cristalina e sua melhor temperatura de trabalhabilidade sejam atingidas para que a malha com os feixes de fibras possam ser prensados e a matriz penetre entre as fibras, formando assim o compósito. Remove-se então a fonte de calor e conduzse o material no molde imediatamente para a prensa para que esse arrefeça com pressão constante e as bolhas que eventualmente possam surgir sejam evitadas.

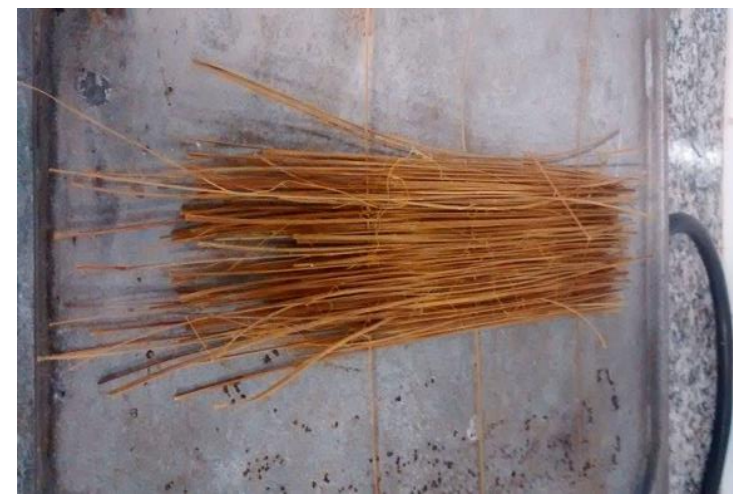

Fonte: próprio autor.

Figura 8: Fibras em uma direção

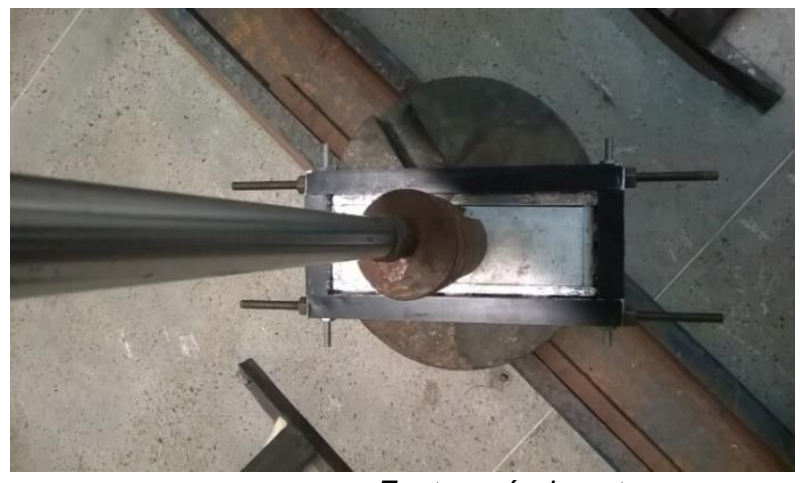

Fonte: próprio autor.

Figura 9: Molde sob ação da prensa

\subsection{Técnicas de Caracterização}

\subsubsection{Ensaio de Tração}

Foi realizado Ensaio de Tração na Máquina EMIC do Laboratório de Ensaios Mecânicos (LEM) da Universidade Federal do Ceará (UFC). A resistência a tração das fibras e seu módulo de Young estão sendo calculados por meio de ensaios de tração em fibras sob a norma ASTM 3379-75 de 1998 (Standard Test Method for Tensile Strength and Young's Modulus for High-Modulus Single-Filament Materials). A figura 10 abaixo apresenta um esquema de como o corpo de prova deve ser montado para o seu respectivo ensaio.

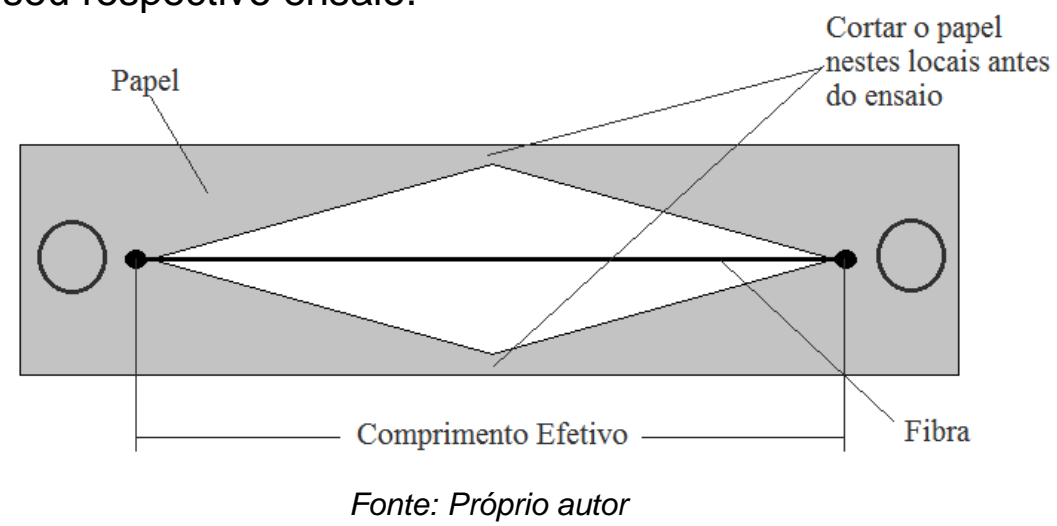

Figura 10: Modelo para ensaio de tração em fibras

Como se pode perceber na figura 10, o ensaio de tração está sendo feito fibra a fibra afixada em um molde de papel, que é cortado no momento do ensaio para que esse não influencie no resultado do ensaio da fibra. 
O ensaio de tração nos materiais plásticos foi realizado sob a norma ASTM D638 (Standard Test Method for Tensile Properties of Plastics). Os corpos de prova foram retirados de placas previamente preparadas para tal finalidade.

\subsubsection{Método de Correlação de Imagens para obtenção do coeficiente de Poisson}

A técnica de correlação de imagem será feita utilizando o CorreliQ4, um software para medições por meio de elementos finitos, que mede os deslocamentos de campo por correlação digital de imagem. O software foi publicado em abril de 2008 em um relatório interno da ENS de Cachan, Universite Paris. A técnica determina pelos deslocamentos identificados pelo software no plano da imagem o coeficiente de Poisson. Em suma, calculam-se os deslocamentos no eixo das abscissas e ordenadas e fazendo uso da seguinte equação, determina-se o valor do coeficiente.

$$
v=-\frac{\xi_{X}}{\xi_{Z}}=-\frac{\xi_{Y}}{\xi_{Z}}
$$

Onde $v$ é o coeficiente de Poisson ou razão de Poisson e $\xi$, com $\mathrm{i}=\mathrm{x}, \mathrm{y}, \mathrm{z} \mathrm{o}$ respectivo deslocamento em cada um dos eixos.

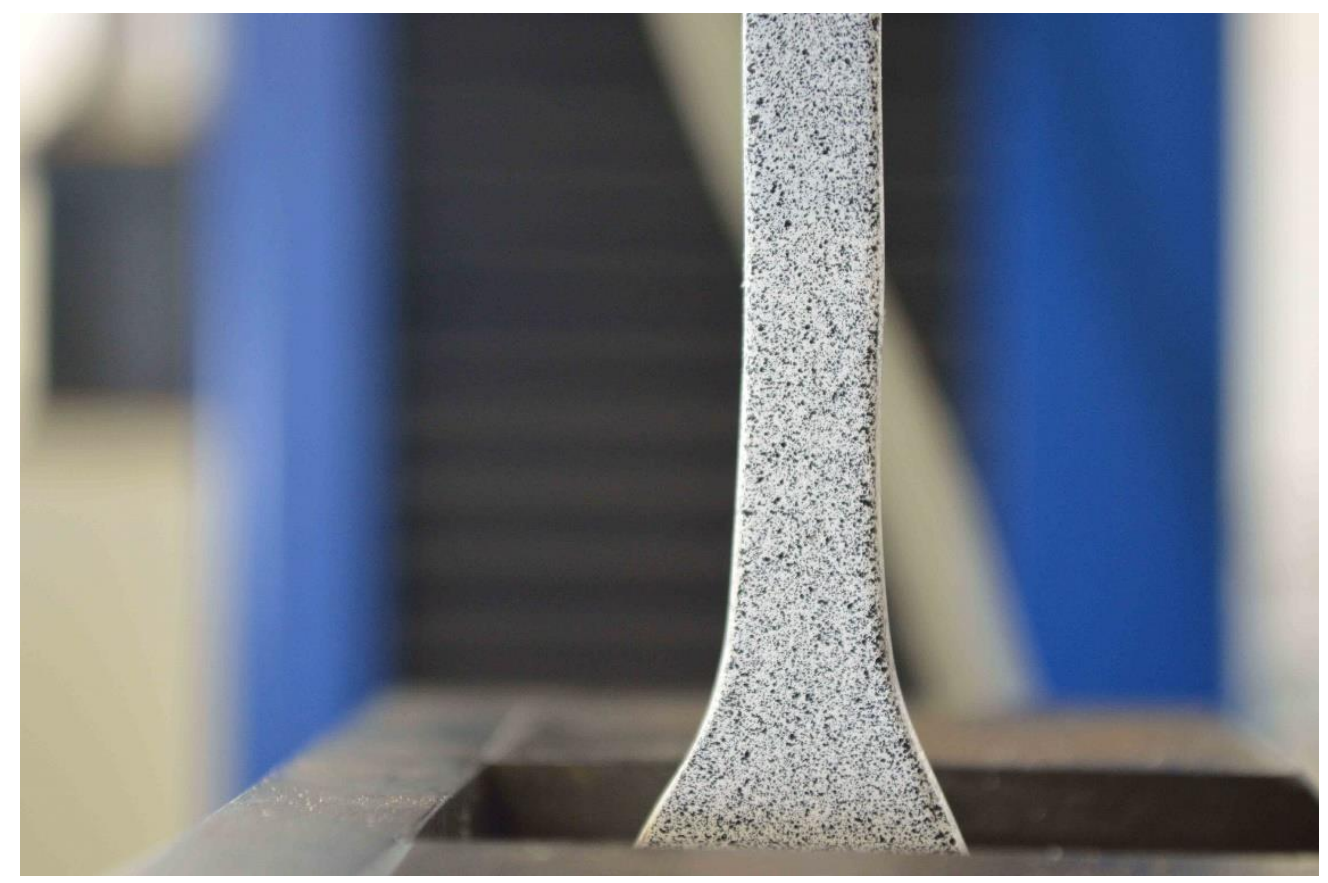

Fonte: Próprio Autor

Figura 11: Corpo de prova preparado para ensaio de tração utilizando o método de correlação de imagem.

\section{RESULTADOS E DISCUSSÃO}

Foram realizados ensaios de tração na Máquina EMIC do Laboratório de Ensaios Mecânicos (LEM) da Universidade Federal do Ceará (UFC) nas fibras, no polipropileno reciclado e virgem. Por último, realizou-se o ensaio no compósito com 
as fibras dispersas. No seguinte tópico, segue o resultado das fibras naturais - sem nenhum tratamento químico-, das fibras mercerizadas a $5 \%$ e $10 \%$ de $\mathrm{NaOH}$ e das fibras após o processo de acetilação por $1 \mathrm{~h}$ e $2 \mathrm{~h}$. As fibras longas de aproximadamente $250 \mathrm{~mm}$, comprimento médio do colmo do bambu, apresentaram diâmetros de $0.5 \mathrm{~mm}$ até $1.0 \mathrm{~mm}$. As medidas do diâmetro foram realizadas 20 vezes cada com micrômetro diminuindo a incerteza na medição e proporcionando dados mais precisos.

\subsection{Obtenção da tensão de ruptura das fibras com diferentes tratamentos}

Aqui constatamos as resistências das fibras individuais após diferentes tratamentos. Na tabela abaixo podemos ver as tensões máximas e deformações alcançadas pelas fibras. E na figura 12, vemos as distribuições de tensões das mesmas.

Tabela 1 : Tabela com os valores médios de Área da seção transversal, Tensão Máxima na ruptura, Módulo de Elasticidade e Deformação na Forca Máxima

\begin{tabular}{|c|c|c|c|}
\hline & $A\left(m^{2}\right)$ & $\begin{array}{c}\text { Tensão Max. } \\
\left(\mathrm{kgf} / \mathrm{mm}^{2}\right)\end{array}$ & $\begin{array}{c}\text { Deformação } \\
(\mathrm{mm})\end{array}$ \\
\hline $\begin{array}{c}\text { Fibra } \\
\text { Natural }\end{array}$ & $\begin{array}{c}0,62 \pm \\
0,02\end{array}$ & $43,51 \pm 2,5$ & $1,98 \pm 0,05$ \\
\hline $\mathrm{NaOH} 5 \%$ & $0,48 \pm 0,02$ & $51,7 \pm 3,9$ & $2,4 \pm 0,66$ \\
\hline $\mathrm{NaOH} 10 \%$ & $0,41 \pm 0,02$ & $49,90 \pm 1,8$ & $1,8 \pm 0,3$ \\
\hline Acetilada 1h & $0,40 \pm 0,02$ & $38,59 \pm 1,9$ & $1,4 \pm 0,2$ \\
\hline Acetilada $2 \mathrm{~h}$ & $0,48 \pm 0,02$ & $34,57 \pm 1,7$ & $1,4 \pm 0,4$ \\
\hline
\end{tabular}

Fonte: Próprio autor

Com o uso do $\mathrm{NaOH}$, observamos um aumento na tensão de ruptura da fibra, devido o seu uso retirar o excesso de lignina junto a fibra. E para o uso de uma menor concentração de $\mathrm{NaOH}$, observou-se uma certa melhoria na tensão de ruptura. 


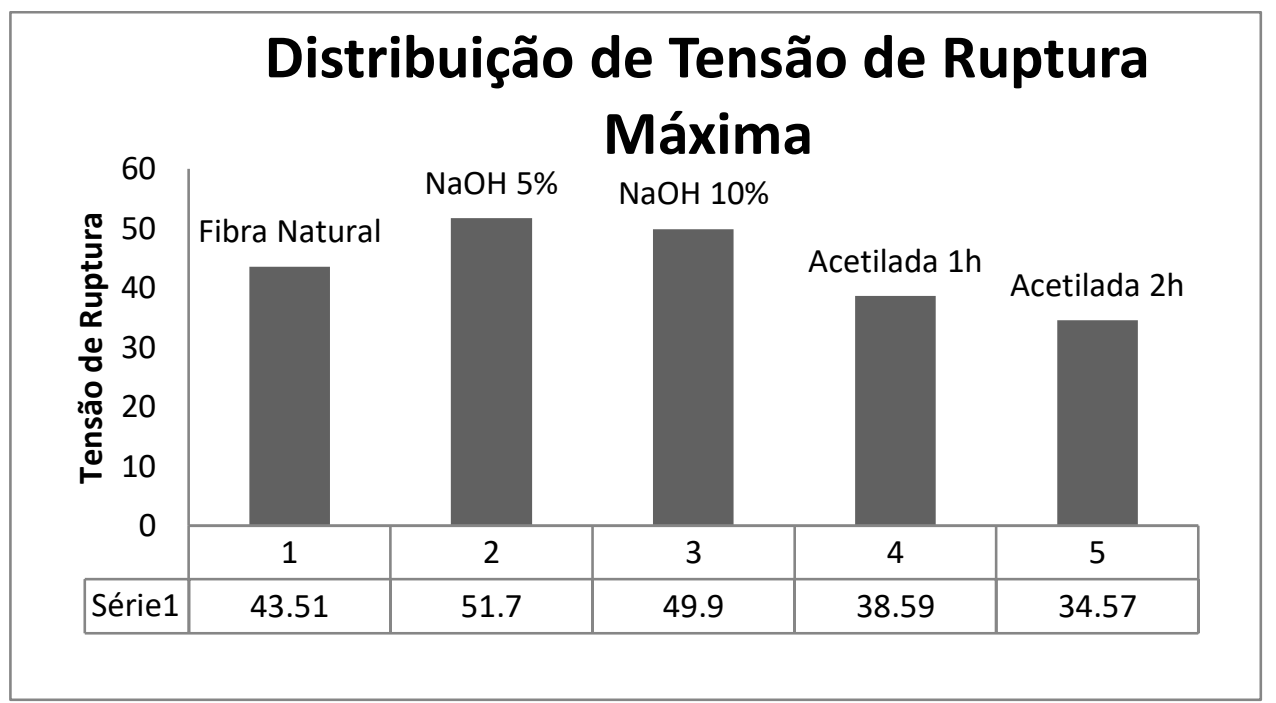

Fonte: Próprio autor

Figura 12: Gráfico de barras esquemático com os valores de tensão de ruptura

Observando as fibras acetiladas notamos uma perda de resistência devido à quantidade de tratamento que danifica a fibra, diminuindo a sua tensão de ruptura, e essa tensão de ruptura tende a diminuir com o aumento do tempo de acetilação, porém o seu uso melhora a compatibilização da fibra com o polipropileno.

\subsection{Resultados das tensões de ruptura dos compósitos}

Abaixo, segue os resultados dos ensaios para a matriz de polipropileno reciclado e virgem juntamente com seus respectivos compósitos. Foram realizados ensaios em 6 corpos de prova para cada material, retirando os 2 dados extremos. Vale ressaltar que nos compósitos foram usadas fibras a $5 \%$ de $\mathrm{NaOH}$, pois foi esse tratamento que obteve melhores resultados nos ensaios das fibras isoladas.

Tabela 2: Tensões de ruptura de cada material

\begin{tabular}{|c|c|c|c|}
\hline $\begin{array}{c}\text { PP Reciclado } \\
\text { (Mpa) }\end{array}$ & $\begin{array}{c}\text { PP Virgem } \\
\text { (Mpa) }\end{array}$ & $\begin{array}{c}\text { Compósito de PP } \\
\text { virgem (Mpa) }\end{array}$ & $\begin{array}{c}\text { Compósito de PP } \\
\text { reciclado (Mpa) }\end{array}$ \\
\hline $\mathbf{1 1 , 2 3}$ & 33,03 & 56,33 & 61,58 \\
\hline $\mathbf{1 1 , 0 5}$ & 30,49 & 55,25 & 41,47 \\
\hline $\mathbf{8 , 7 5}$ & 27,51 & 49,94 & 38,20 \\
\hline $\mathbf{6 , 4 1}$ & 26,47 & 46,65 & 30,89 \\
\hline Desvio & Desvio & Desvio Padrão & Desvio Padrão \\
\hline Padrão & Padrão & & 13,13 \\
\hline $\mathbf{2 , 2 7}$ & 2,97 & 4,55 & Média \\
\hline Média & Média & Média & 43,04 \\
\hline $\mathbf{9 , 3 6}$ & 29,38 & 52,04 & \\
\hline
\end{tabular}

Fonte: Próprio autor 


\section{Distribuição de Tensão de Ruptura máxima}

— PP Reciclado (Mpa) — PP Virgem (Mpa) — Compósito de PP reciclado (Mpa) — Compósito de PP virgem (Mpa)

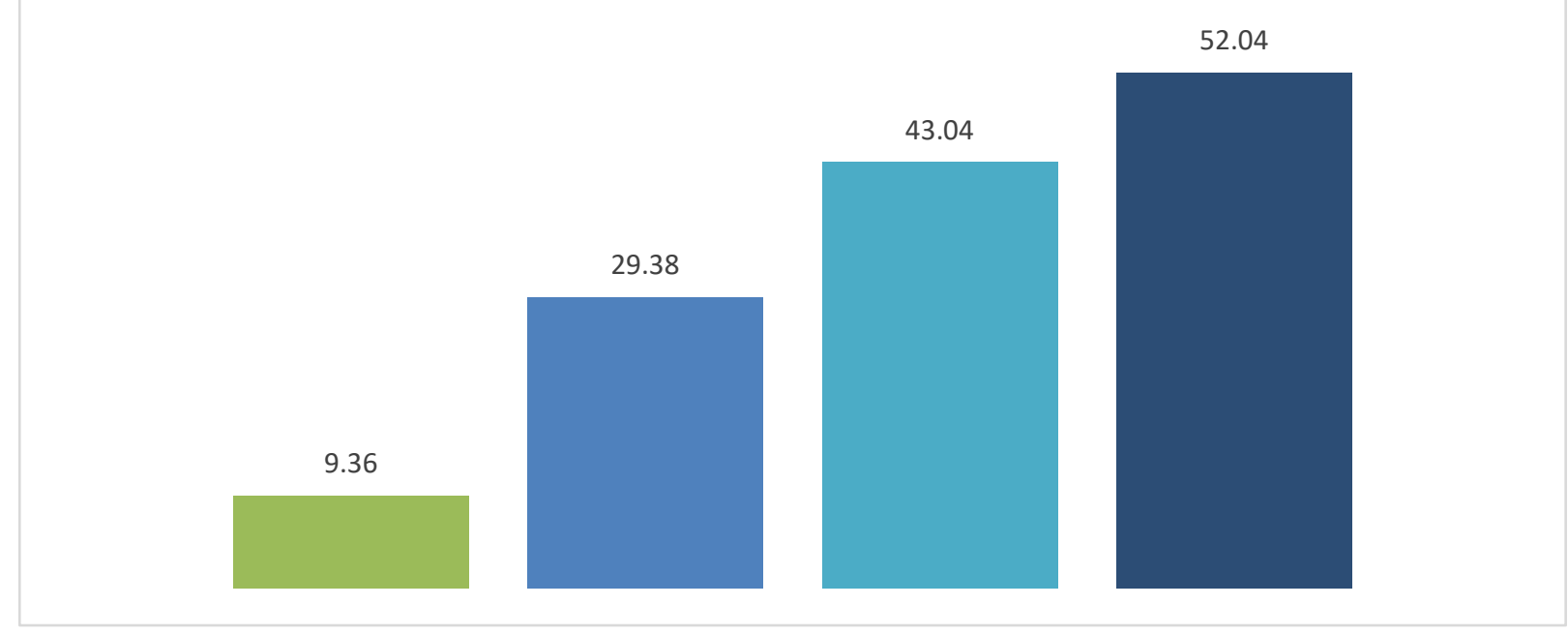

Fonte: Próprio autor

Figura 13: Gráfico esquemático com as tensões de ruptura

\subsection{Coeficiente de Poisson obtido por Correlação de Imagens}

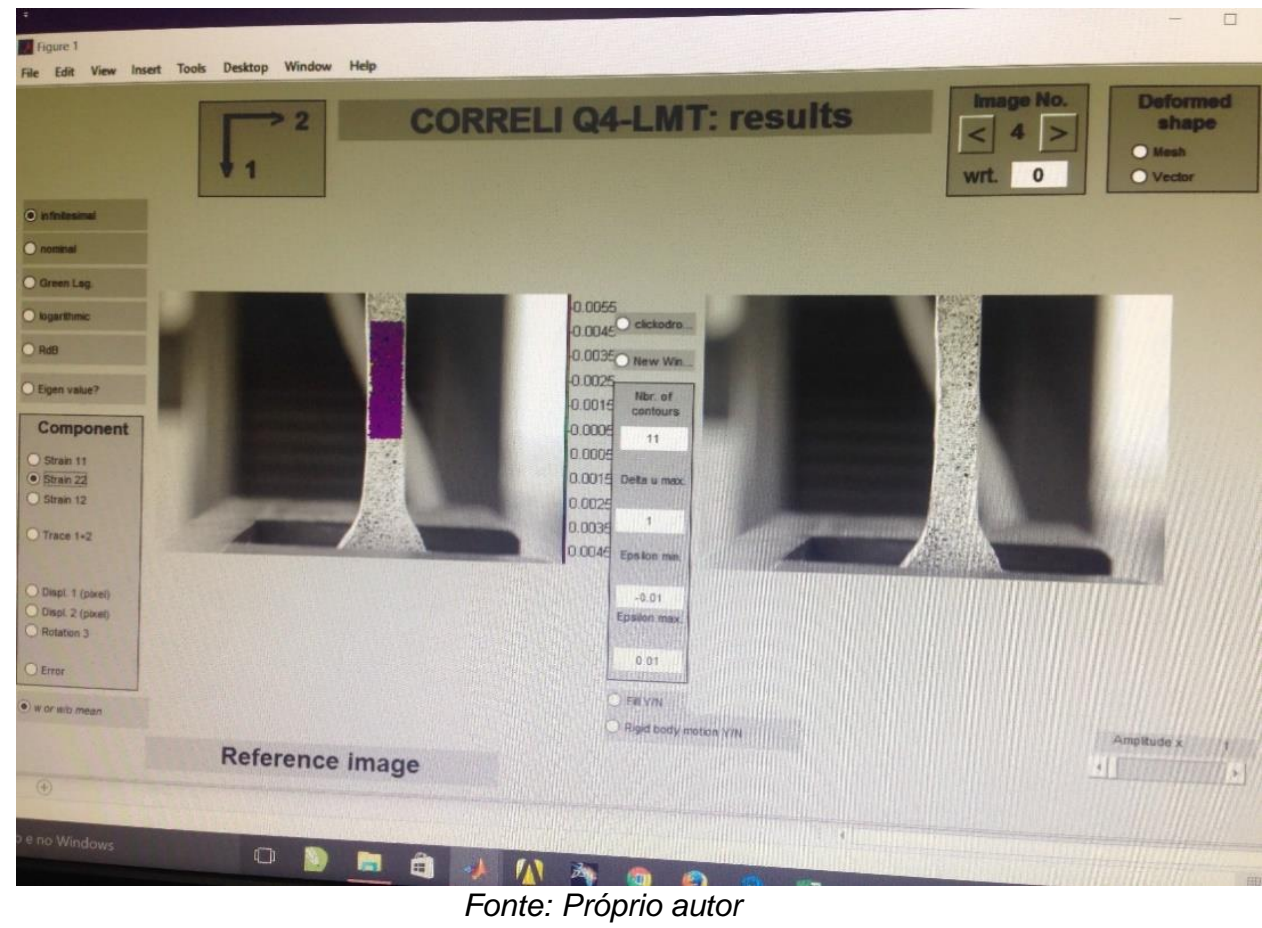

Figura 14: Obtenção dos dados do Coeficiente de Poisson, pelo Correli. 
Como o polipropileno é um polímero muito flexível ele possui altos valores de Coeficiente de Poisson, aproximadamente 0,45 , mas com o uso das fibras observouse um aumento na rigidez do material, como podemos constatar na tabela abaixo:

Tabela 4: Resultado da Média do Coeficiente de Poisson e sua Variância.

\begin{tabular}{|c|c|}
\hline Ensaios & Coeficiente de Poisson \\
\hline $\mathbf{1}$ & 0,5 \\
\hline $\mathbf{2}$ & 0,38 \\
\hline $\mathbf{3}$ & 0,5 \\
\hline $\mathbf{4}$ & 0,33 \\
\hline $\mathbf{5}$ & 0,28 \\
\hline $\mathbf{6}$ & 0,15 \\
\hline Coeficiente de Poisson médio & 0,36 \\
\hline Desvio Padrão dos dados & 0,6 \\
& \\
\hline
\end{tabular}

Fonte: Próprio autor

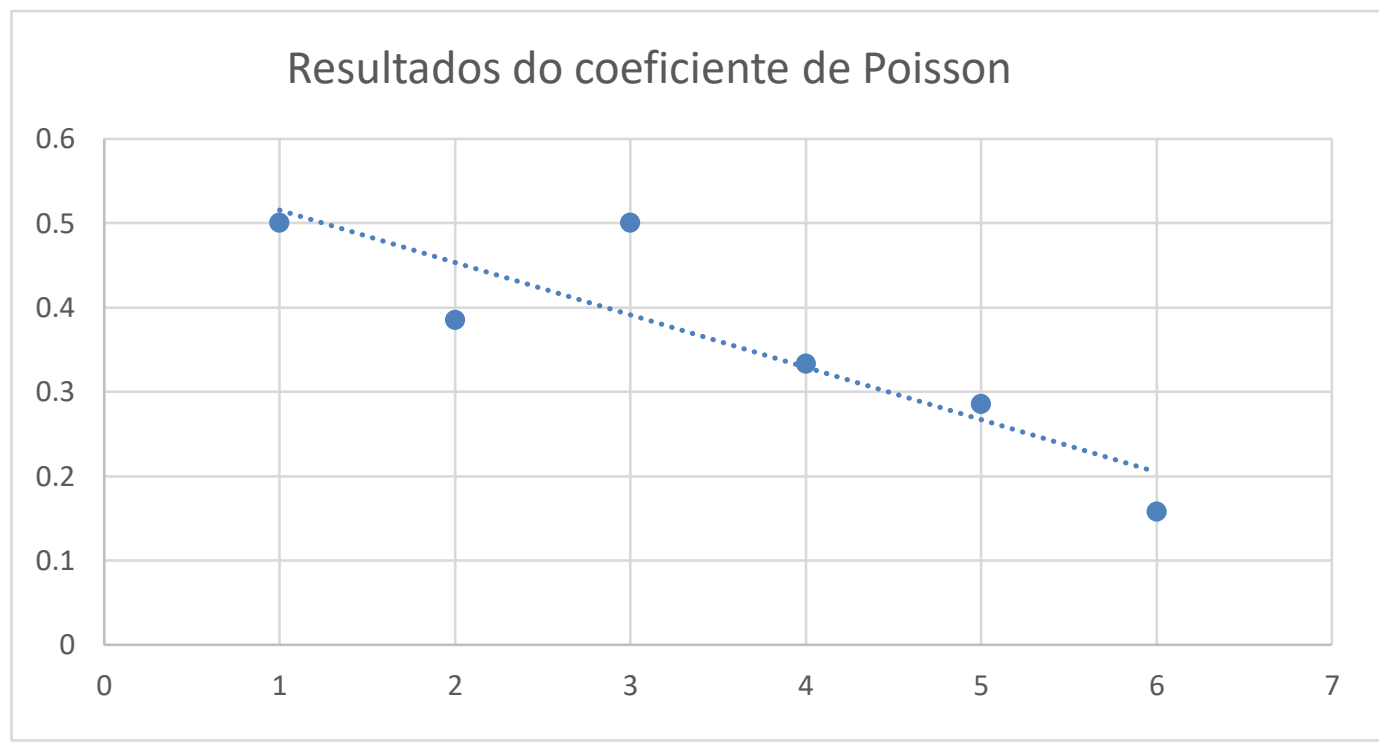

Fonte: Próprio autor

Figura 15: Gráfico da Variância.

Como podemos observar com a adição das fibras ocorreu uma diminuição do Coeficiente de Poisson, pois houve um aumento da rigidez do material na direção do ensaio o que contribuiu para esta diminuição.

Logo, percebe-se que a adição das fibras melhorou a propriedade de resistência mecânica do compósito. Somado a isso, os dados mostram que a 
matriz de maior eficiência é a do tipo virgem, pois apresenta menos impurezas, isto é, menos concentradores de tensão.

\section{CONCLUSÃO}

Após a obtenção dos dados, percebeu-se que a adição das fibras melhorou as propriedades mecânica do compósito resultante. Mostrando, portanto, resultados promissores o desenvolvimento desses materiais, assim como para aplicações específica, por exemplo, em automóveis em substituição aos materiais tradicionais, promovendo assim um material mais barato e de melhores propriedade mecânica, além de uma alta leveza. Além disso, por meio da técnica de correlação de imagem, conseguiu-se calcular o coeficiente de Poisson do material. Verificou-se também que a matriz de melhor eficiência é do tipo virgem em comparação com a do tipo reciclada. No entanto, o uso dessa última é importante devido suas características de material sustentável.

Em suma, os resultados mostram que o compósito em estudo apresenta propriedades mecânica e característica sustentáveis que estimulam um estudo mais detalhado visando a aplicação desse material. Vale ressaltar a necessidade de outros ensaios para melhor caracterização mecânica, como ensaio de impacto.

\section{Agradecimentos}

Agradecemos à Fundação Cearense de Apoio ao Desenvolvimento Científico e Tecnológico ( FUNCAP ) e ao CNPq pela concessão de bolsa, ao Laboratório de Produtos e Tecnologia em processo (LPT) e ao Laboratório da Mecânica da Fadiga e Fratura (LAMEFF) pelo espaço e disponibilidade de materiais e equipamentos. Ao ENS de Cachan, Universite Paris, pela disponibilidade do software CorreliQ4.

\section{REFERÊNCIAS}

1 CANEVAROLO Jr., Sebastião V. CIÊNCIA DOS POLIRNEROS: UM TESTO BÁSICO PARA TECNÓLOGOS E ENGENHEIROS, São Paulo, Artliber Editora, 2002. Estrutura de referência de artigo: Autor(es). Título do artigo. Título do periódico. Ano; volume(número): página inicial e final do artigo.

2 MALLICK, P. K. Figueira-do-reino composites: materials, manufacturing and design. Ne wYork, Marcel Dekker, p. 312, 1988.

3 MARINELLI L., Marcos R. M., D. Ambrósio, Márcio Kobayashi, Antônio D. Nobre, DESENVOLVIMENTO DE COMPÓSITOS POLIMÉRICOS COM FIBRAS VEGETAIS NATURAIS DA BIODIVERSIDADE: UMA CONTRIBUIÇÃO PARA A SUSTENTABILIDADE AMAZÔNICA, Polímeros: Ciência e Tecnologia, vol. 18, no 2, p. 92-99, 2008. 
4 KURUVILLA, J.; THOMAS, S.; PAVITHRAN, C. Effect of chemical treatment on the tensile properties of short sisal fiber-reinforced polyethylene composites.Polymer, v.37,n.23,p.5139-49,1996.

5 DOS SANTOS, A. M. Estudo de compósitos híbridos polipropileno / fibras de vidro e coco para aplicações emengenharia.76p.Dissertação (Mestrado em Engenharia Mecânica, Setor de Tecnologia, Universidade Federal do Paraná) Curitiba, Paraná, 2006.

6 ROMÃO, C. M. N. Estudo do comportamento mecânico de materiais compósitos de matriz polimérica reforçados com fibras naturais.147p.Dissertação(Mestrado em Engenharia Mecânica da Faculdade de Engenharia da Universidade do Porto) 2003 